\section{SOI: 1.1/TAS DOI: 10.15863/TAS International Scientific Journal Theoretical \& Applied Science}

\author{
p-ISSN: 2308-4944 (print) e-ISSN: 2409-0085 (online) \\ Year: $2017 \quad$ Issue: $09 \quad$ Volume: 53
}

Published: $30.09 .2017 \quad$ http://T-Science.org

SECTION 31. Economic research, finance, innovation, risk management.

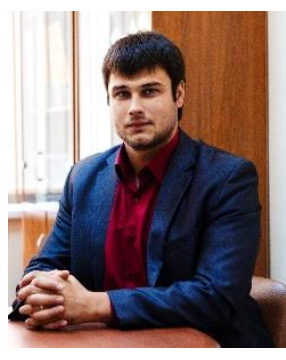

Artem Alekseevich Golovin candidate of economic sciences, assistant professor of the department of customs affairs and global economy, South West State University (SWSU)

Kursk, Russian Federation cool.golovin2011@yandex.ru

Aleksej Anatol'evich Golovin doctor of economic sciences, assistant professor, professor of the department of economic security and taxation, South West State University (SWSU)

Kursk, Russian Federation dr.golovin2013@yandex.ru

Marina Anatol'evna Parhomchuk doctor of economic sciences, assistant professor, professor of the department of customs affairs and the global economy, South West State University (SWSU)

Kursk, Russian Federation marinaanatollevna@yandex.ru

\title{
INTEGRATED ASSESSMENT OF THE CONDITIONS FOR EXTERNAL TRADE OF THE BRICS COUNTRIES
}

Abstract: The work evaluates the factors influencing the development of foreign trade of the BRICS countries. The research is based on the efficiency indicators of foreign trade logistics and customs organization. Estimating the time of delivery of goods in export-import transactions allowed to determine the effectiveness of foreign trade institutions. Based on the results of the study, conclusions were made and the main directions of simplifying foreign trade operations were identified.

Key words: foreign trade, BRICS, logistics performance index, customs authorities, delivery time, export, import.

Language: Russian

Citation: Golovin AA, Golovin AA, Parhomchuk MA (2017) INTEGRATED ASSESSMENT OF THE CONDITIONS FOR EXTERNAL TRADE OF THE BRICS COUNTRIES. ISJ Theoretical \& Applied Science, 09 (53): 216-220.

Soi: http://s-o-i.org/1.1/TAS-09-53-33 Doi: crossef https://dx.doi.org/10.15863/TAS.2017.09.53.33

\section{КОМПЛЕКСНАЯ ОЦЕНКА УСЛОВИЙ ВНЕШНЕЙ ТОРГОВЛИ СТРАН БРИКС}

Аннотация: В работе проводится оценка факторов, влияющих на развитие внешней торговли стран БРИКС. В основу исследования положены показатели эффективности внешнеторговой логистики и организации таможенного дела. Оценка времени доставки товаров при экспортно-импортных операциях позволила определить результативность деятельности внешнеторговых институтов. По результатам проведённого исследования сформулированы выводы и определены основные направления упрощения внешнеторговых операций.

Ключевые слова: внешняя торговля, БРИКС, индекс эффективности логистики, таможенные органы, время доставки, экспорт, импорт.

\section{Introduction}

Необходимость развития международной торговли определяется рядом объективных факторов. Во-первых, развитие внешней торговли является неотъемлемым условием капиталистической модели экономики. Вовторых, внешняя торговля способствует реализации сравнительных преимуществ. Втретьих, внешняя торговля является важным источником доходов государства.

ISPC Innovations in science, 
На развитие внешней торговли значительное влияние оказывают внешнеторговые институты. К данным институтам можно отнести таможенные органы, экспедиторские и транспортные компании и другие организации, от деятельности которых зависит скорость и простота осуществления торговых операций. Чем меньше барьеров и выше скорость товарооборота, тем более либерализованной является внешняя торговля.

Оценка условий внешней торговли проводится по ряду показателей, одним из которых является «количество документов, требующихся для каждой партии товаров при экспорте или импорте». Данный показатель получают путём анализа всех операций конкретной страны за год с определением среднего количества документов, необходимых для осуществления одной экспортно-импортной операции (документы, необходимые для оформления министерствами, таможенными органами, торговыми терминалами, органами медицинского, ветеринарного, технического и другого контроля, а также банками).

Вторым направлением исследования является анализ индекса эффективности логистики/Logistics Performance Index (ИЭЛ/LPI) и показателей его формирующих. ИЭЛ позволяет дать оценку качества внешнеторговой логистики по шести компонентам, таким как эффективность работы таможенных органов, качество торговой и транспортной инфраструктуры, простота организации международных поставок товаров, компетентность и качество логистических услуг, возможность отслеживания грузов, соблюдение сроков поставок.

Третье направление основано на анализе мнений руководителей предприятий ВЭД об эффективности таможенных процедур посредством показателя «бремя таможенной процедуры». Показатель колеблется от 1 до 7 , чем больше значение, тем эффективней организация процесса таможенного оформления в конкретной стране.

\section{Materials and Methods}

За 2005-2014 гг. потребность в документах для экспортных операций в странах БРИКС не изменилась. Наибольшее количество экспортных документов необходимо в Российской Федерации и ЮАР (7). Затем следует Китай, где данный показатель составляет 4,4. Наиболее простая процедура экспорта в Бразилии и Индии, что определяется значениями показателя равными 3,7 и 3,3 соответственно (рис. 1).

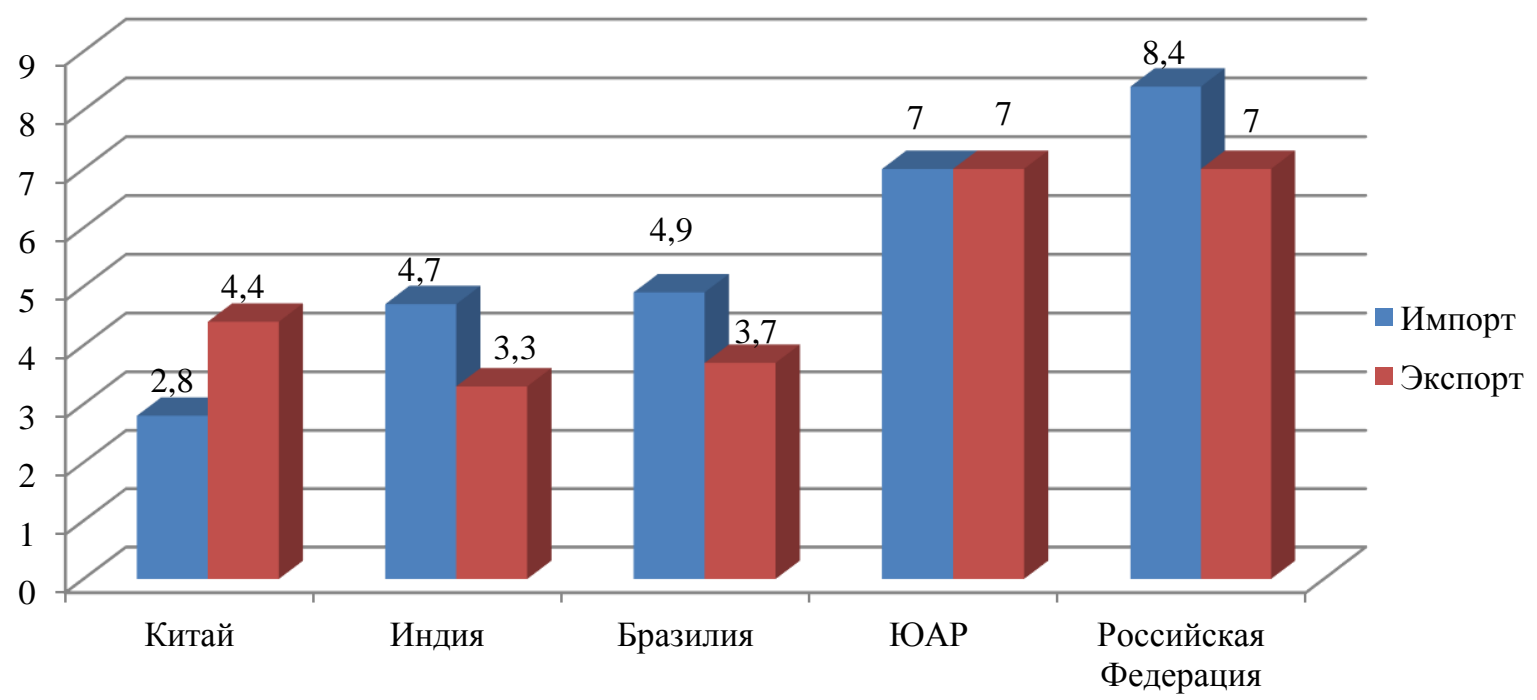

Рисунок 1 - Количество документов требующихся для осуществления экспортно-импортных операций [1]

\begin{abstract}
Несколько иная ситуация сложилась с показателем дколичество докуннтов необходимых для осуществления импорта товаров». С 2005 г. по 2014 г. количество документов необходимых для импорта в Китай сократилось с 3,3 до 2,8, что соответствует наименьшему значению среди стран БРИКС. В Индии, Бразилии, ЮАР и Российской Федерации количество документов необходимых для
\end{abstract}

осуществления импорта осталось неизменным и составило 4,7, 4,9, 7, и 8,4 соответственно [10, с. 27].

Оценка данного показателя по миру в целом, позволяет сделать вывод о том, что наиболее сложно осуществлять экспортные операции в Узбекистане, где потребуется 13 документов. Мировым лидером по простоте документального оформления экспортных операций является 
США. В США значение данного показателя составляет 1,8. Затем следуют Франция, Ирландия и Япония с количеством документов равным двум. Всего три документа потребуется для осуществления экспорта в Панаме, Италии, Гонконге, Южной Корее, Сингапуре, Австрии, Швеции, Эстонии, ОАЭ, Канаде и Швейцарии [9, c. 95].

Наибольшее количество документов для импорта товаров требуется в Центральной Африканской Республике (17). Узбекистан расположился на втором месте с 15 документами необходимыми для оформления импортных операций. Наименьшее количество документов для импортных поставок требуется во Франции и Ирландии (2). Для импорта в США потребуется в среднем 3 документа.

Исследование показателя «количество документов, экспорта/импорта», забюрократизированности операций в РФ. Данная ситуация оказывает негативное влияние на развитие внешней торговли. Кроме того, отсутствуют тенденции снижения бюрократических барьеров. Организация Таможенного союза ЕАЭС не привела к уравниванию количества документов, необходимых для оформления внешнеторговых операций в странах-участниках [5, с. 214].

Уровень развития внешнеторговой логистики определяет эффективность внешней торговли и, как следствие, имеет ключевое значение для экономического роста страны. Оценка внешнеторговой инфраструктуры проводится на основе индекса эффективности логистики. Данный показатель формируется на основе результатов опросов внешнеторговых и экспедиторских операторов, служб экспрессдоставки и предприятий ВЭД (табл. 1).

Оценка эффективности внешнеторговой логистики стран БРИКС в 2016 г. [2]

Таблица 1

\begin{tabular}{|l|c|c|c|c|c|}
\hline Показатель Сана & Китай & Бразилия & Индия & Россия & ЮАР \\
\hline Эффективность работы таможенных органов & 3 & 3 & 3 & 2 & 4 \\
\hline $\begin{array}{l}\text { Качество торговой и транспортной } \\
\text { инфраструктуры }\end{array}$ & 4 & 3 & 3 & 2 & 4 \\
\hline $\begin{array}{l}\text { Простота организации международных } \\
\text { поставок товаров }\end{array}$ & 4 & 3 & 3 & 2 & 4 \\
\hline $\begin{array}{l}\text { Компетентность и качество логистических } \\
\text { услуг }\end{array}$ & 4 & 3 & 3 & 3 & 4 \\
\hline Возможность отслеживания грузов & 4 & 3 & 4 & 3 & 4 \\
\hline Соблюдение сроков поставок & 4 & 3 & 4 & 3 & 4 \\
\hline Общий индекс эффективности логистики & 3,8 & 3,0 & 3,3 & 2,5 & 4,0 \\
\hline
\end{tabular}

Оценка эффективности логистики стран БРИКС свидетельствует о том, что ЮАР обладает наиболее развитой внешнеторговой логистической инфраструктурой. Затем следуют Китай, Индия, Бразилия и завершает рейтинг Россия со значением индекса эффективности логистики 2,5. Следует отметить, что не одна страна мира, участвующая в оценке эффективности логистики, не имеет наивысшего балла. Таким образом, ЮАР стоит наравне со странами с наиболее упрощённой системой внешней торговли. Несмотря на то, что экспорт ресурсов и импорт потребительских товаров, машин, оборудования, электроники играют значительную роль в экономике России, органами государственной власти не созданы условия для стимулирования внешнеторговой деятельности [4, с. 108].

Бремя таможенной процедуры в странах БРИКС оценено в 4 балла, за исключением Бразилии, со значением 3. Единственная страна БРИКС, демонстрирующая снижение эффективности системы таможенного оформления это Китай. За 2007-2016 гг. эффективность таможенных процедур Китая снизилась на 5\%. Наибольший рост эффективности демонстрирует Россия, так за исследуемый период он составил 39\%. Данная ситуация обусловлена совершенствованием и унификацией таможенного законодательства в рамках ЕАЭС [6, с. 351].

К странам с наиболее эффективным таможенным оформлением, оценённым в 6 баллов, относят Финляндию, Грузию, Ирландию, ОАЭ, Сингапур, Люксембург, Нидерланды, Новую Зеландию и Гонконг. Наименьшая эффективность таможенной деятельности, равная 2-м баллам, имеет место в Чаде, Венесуэле, Гаити, Никарагуа и Аргентине.

Рассмотренные условия внешней торговли, наравне с географическими факторами, в значительной степени влияют на время осуществления торговых операций. 
С целью оценки времени доставки товаров конечным потребителям определяют количество дней, требующихся для осуществления экспорта и импорта товаров. Учёт времени начинается с момента инициирования процедуры экспорта/импорта и выполняется до её завершения. Процедура экспорта/импорта может инициироваться как на внутренних таможенных постах, расположенных в глубине страны, так и расположенных на границе. На время нахождения товаров в пути, наравне с условиями рассмотренными ранее, при экспортноимпортных операциях влияют: уровень развития транспортной инфраструктуры, географическое положение страны экспортёра и импортёра, технологии доставки товаров [3, с. 125].

Оценка времени осуществления процедуры экспорта товаров, стран БРИКС, свидетельствует о том, что все страны группы, за исключением ЮАР, увеличили время доставки товаров. Данная ситуация вызвана расширением географии реализации товаров, но все же это следует оценить с негативной стороны. ЮАР сократил на 9 дней время доставки товаров при процедуре экспорта с 25 до 16 дней. Поставки товаров из России имеют наибольшее время нахождения пути, учитывая, что основными торговыми партнёрами являются ЕС и Китай то данная тенденция является отрицательной.

После России с наибольшим временем экспорта товаров следует Китай. Среднее время экспорта из Китая составляет 21 день, а из Гонконга и Сингапура 6 дней, на основании чего можно сделать вывод, что данная ситуация вызвана значительной территорией страны и сложным таможенным оформлением. Для Китая основными торговыми партнёрами являются США и страны ЕС [7, с. 55].

Динамика времени импорта товаров в страны БРИКС, в общем виде, совпадает со временем экспорта, т.е. время импорта товаров во все страны увеличилось, за исключением ЮАР. В ЮАР оно сократилось с 35 дней в 2005 г. до 21 дня в 2014 г. что свидетельствует о перераспределении торговых потоков в сторону географически более близких стран [8, с. 55].

Китай и Россия демонстрируют наибольший, среди стран БРИКС, рост времени импорта товаров (68 и $20 \%$ соответственно). Данная ситуация вызвана диверсификацией внешних торговых связей, значительной территорией, протяжёнными внутренними транспортными путями, а также расположением основных производящих отраслей в глубине страны.

\section{Conclusion}

Проведённая комплексная оценка внешнеторговой логистики свидетельствует о том, что наиболее благоприятные условия внешней торговли имеют место в ЮАР. В Китае ситуация незначительно ухудшилась, что было вызвано ужесточением государственного контроля в целях защиты национальных интересов. Индия, реализуя политику умеренной экономической самодостаточности, обладает средними условиями внешнеторговой логистики. Политика в области развития внешней торговли Бразилии и России наиболее схожа и находится на близком уровне.

В России самое сложное таможенное оформление, однако, имеет место тенденция снижения бремени таможенной процедуры, что положительно. Общий индекс эффективности логистики России наименьший среди стран БРИКС, что вызвано слабым развитием внешнеторговой инфраструктуры. Положительным моментом является рост данного показателя за 9 лет на 26,6\%.

Оценка условий осуществления внешней торговли позволило определить для стран БРИКС, следующие ключевые направления развития:

1. России и Китаю необходимо обеспечить снижение времени экспорта товаров посредством развития транспортной инфраструктуры и упрощения таможенных процедур.

2. России, Бразилии и Индии необходимо направить усилия на совершенствование системы отслеживания грузов, соблюдение сроков поставок, повышение качества таможенных и логистических услуг.

3. России необходимо реализовать комплекс мер, направленных на повышение эффективности таможенных органов в рамках действующего Евразийского экономического союза.

References:

1. (2017) Vsemirnaja statistika [Jelektronnyj resurs]: Available: http://world-statistics.org/ (Accessed: 02.09.2017).
2. (2017) Vsemirnyj bank [Jelektronnyj resurs]: Available: https://lpi.worldbank.org/ (Accessed: 02.09.2017). 


\begin{tabular}{l|lrl|l|ll} 
& ISRA (India) & $=\mathbf{1 . 3 4 4}$ & SIS (USA) & $=\mathbf{0 . 9 1 2}$ & ICV (Poland) & $=\mathbf{6 . 6 3 0}$ \\
Impact Factor: & ISI (Dubai, UAE) $=\mathbf{0 . 8 2 9}$ & PUHL (Russia) $=\mathbf{0 . 2 0 7}$ & PIF (India) & $=\mathbf{1 . 9 4 0}$ \\
& GIF (Australia) & $\mathbf{0 . 5 6 4}$ & ESJI (KZ) & $=3.860$ & IBI (India) & $=\mathbf{4 . 2 6 0}$ \\
& JIF & $\mathbf{1 . 5 0 0}$ & SJIF (Morocco) & $=\mathbf{2 . 0 3 1}$ & & \\
\hline
\end{tabular}

3. Gizjatova T.A. (2015) Puti ukreplenija pozicij Rossii v mirovom rejtinge LPI / T.A. Gizjatova, S.P. Koroleva // Sinergetika prirodnyh, tehnicheskih i social'no-jekonomicheskih sistem. - 2015. - № 13. - p. 125-131.

4. Dashkevich A.V. (2016) Ocenka logisticheskogo potenciala zarubezhnyh stran / A.V. Dashkevich // Problemy upravlenija (Minsk). - 2016. - № 4 (61). - p. 108-112.

5. Zohidov A.A. (2012) Sovremennye logisticheskie centry: sushhnost', osobennosti i tendencii razvitija / A.A. Zohidov // Jekonomicheskoe vozrozhdenie Rossii. - 2012. - № 1. - p. 214-220.

6. Kurganov V.M. (2014) Metodologicheskie problemy opredelenija mezhdunarodnogo rejtinga jeffektivnosti logistiki / V.M. Kurganov // Vestnik Tverskogo gosudarstvennogo universiteta. Serija: Jekonomika i upravlenie. 2014. - № 4-2. - p. 351-358.
7. Pavlenko O.A. (2017) Ocenka tranzitnogo potenciala mezhdunarodnyh transportnyh koridorov «Primor'e-1» i «Primor'e-2»/ O.A. Pavlenko // Tamozhennaja politika Rossii na Dal'nem Vostoke. - 2017. - № 1 (78). - p. 5563.

8. Skuzovatova N.V. (2016) Sovremennoe sostojanie rossijskoj logistiki: problemy, reshenija / N.V. Skuzovatova // Intellekt. Innovacii. Investicii. - 2016. - № 6. - p. 55-59.

9. Sovetbekov B. (2015) Metodologija indeksa jeffektivnosti logistiki / B. Sovetbekov // Vestnik Tadzhikskogo tehnicheskogo universiteta. - 2015. - № 3 (31). - p. 95-96.

10. Shherbanin Ju.A. (2017) Logistika i popytki izmerenija: indeks jeffektivnosti logistiki / Ju.A. Shherbanin // Voprosy novoj jekonomiki. - 2017. - № 1 (41). - p. 27-34. 